\title{
Mondor's Disease: A Rare Cause of Chest Pain in the Emergency Department
}

\author{
Brett Todd ${ }^{1}$, Linnea Nierenberg ${ }^{2}$, Jacob Price ${ }^{3}$ \\ 1. Emergency Medicine, Beaumont Hospital, Royal Oak, USA 2. Emergency Medicine, Oakland University William \\ Beaumont School of Medicine, Rochester, USA 3. Emergency Medicine, St. Mary Mercy Hospital, Livonia, USA
}

Corresponding author: Linnea Nierenberg, lnierenberg@oakland.edu

\begin{abstract}
Thrombophlebitis of a subcutaneous vein, known as Mondor's disease, is a rare cause of chest pain and can mimic several more life-threatening diseases. Mondor's disease can be caused by trauma, or hypercoagulable states; however, in many cases the etiology is unknown. Mondor's disease is usually self-limited and can be managed conservatively. In this case report, we highlight a 52-year-old male patient who presented to our emergency department with chest pain caused by Mondor's disease mimicking a pulmonary embolism. Although a rare and benign diagnosis, Mondor's disease should be part of the differential diagnosis of chest pain and can be made on the basis of a thorough history and physical examination alone. Recognition of Mondor's disease could reduce costs and risks of further testing for patients presenting with chest pain.
\end{abstract}

Categories: Emergency Medicine

Keywords: chest pain, thrombophlebitis, mondor's disease

\section{Introduction}

Chest pain presents a diagnostic challenge to the clinician with etiologies that range from life-threatening to benign [1]. Often an extensive diagnostic evaluation is performed; however, in some instances the history and physical examination alone may reveal the diagnosis. Thrombophlebitis of the subcutaneous veins of the chest wall, known as Mondor's disease, is one such diagnosis. It is most frequently identified in the chest wall, although it has also been described in the groin, penis, and antecubital fossa [2]. Below we present a case of chest pain seen in our emergency department, mimicking a pulmonary embolism, that was ultimately diagnosed as Mondor's disease. The patient described in this case presented with symptoms classically seen in Mondor's disease-a hard, indurated, cord-like mass that is painful upon palpation without overlying erythema [3].

\section{Case Presentation \\ History}

Received 12/19/2019

Review began 01/06/2020 Review ended 02/05/2020 Published 02/07/2020

\section{(c) Copyright 2020}

Todd et al. This is an open access article distributed under the terms of the Creative Commons Attribution License CC-BY 4.0., which permits unrestricted use, distribution, and reproduction in any medium, provided the original author and source are credited.
A 52-year-old African American male presented to the emergency department complaining of pleuritic, sharp pain in his right chest wall that had begun three days prior to arrival. The pain had since worsened in intensity, and did not radiate. He had taken acetaminophen without relief of his symptoms. The patient denied any fever, cough, shortness of breath, headache, or rash. His review of symptoms was otherwise negative. The patient had no significant past medical history and was taking no medications. He denied any recent history of surgery or trauma, but did note weight lifting two days prior to the onset of symptoms. Family history was negative for coagulopathies and autoimmune conditions.

\section{Exam findings}

Vital signs on arrival were blood pressure $146 / 97$, heart rate 97 , temperature $36.2^{\circ} \mathrm{C}$, respiratory rate 20 , and $\mathrm{SpO}_{2} 99 \%$ on room air. He was alert and oriented, and in no acute distress. Lung sounds were clear

bilaterally and heart sounds were normal. A raised cord was visible crossing from the epigastrium across the right breast toward the axilla, that was tender to palpation and mobile. There was no warmth, erythema, or rash overlying the cord. Head/eyes/ears/nose/throat, abdominal, and neurological examinations were unremarkable.

\section{Diagnostic evaluation}

Basic metabolic panel and troponin levels were normal, and a complete blood count and differential was unremarkable with platelets of $212 \mathrm{bil} / \mathrm{L}$. Chest radiograph showed clear lung fields but did reveal remote right-sided posterior fractures of ribs five through eight. Given the pleuritic nature of the pain, a computed tomography pulmonary angiogram was ordered to rule out pulmonary embolism. As shown in Figure 1, it revealed a subtle density in the right chest wall over the area of the palpable cord, with no evidence of a pulmonary embolism. The diagnosis of superficial chest wall thrombophlebitis, or Mondor's disease, was made. 


\section{Cureus}

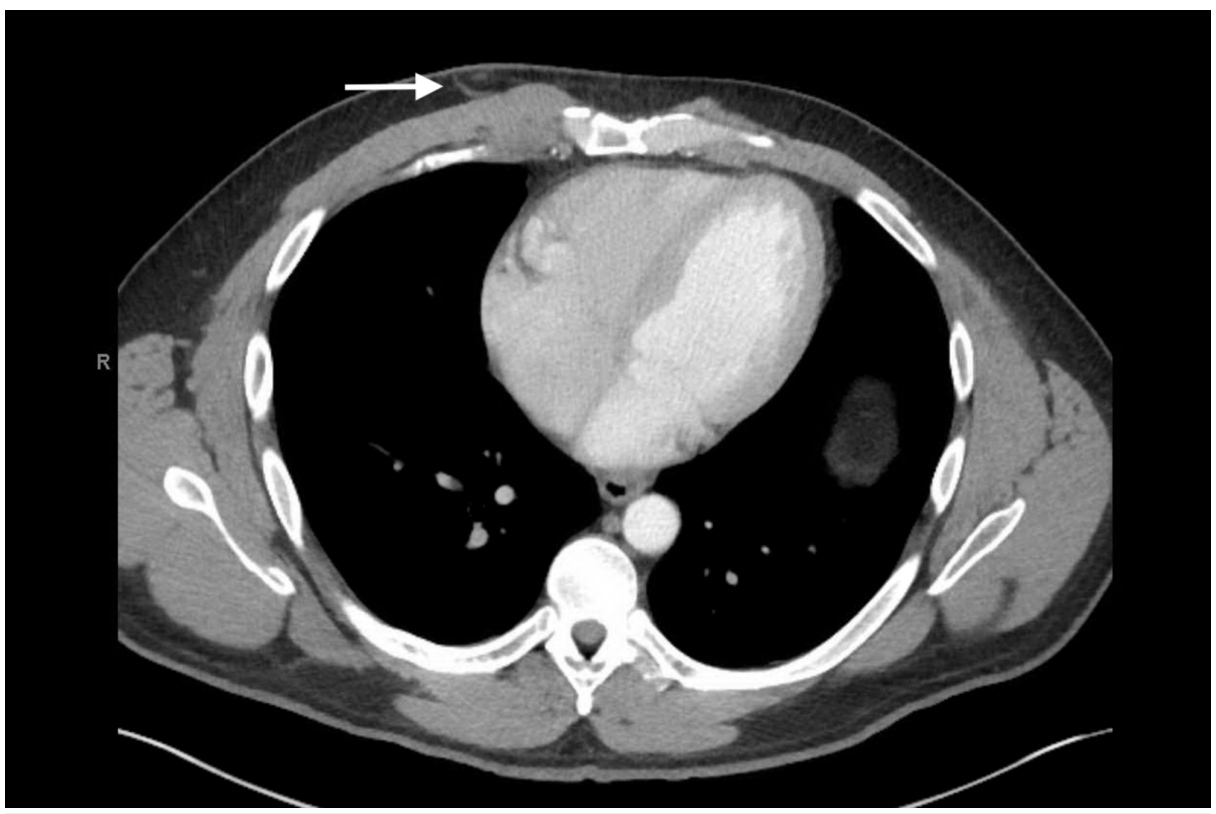

FIGURE 1: Computed tomography scan showing a subcutaneous thrombosis in the right chest wall.

\section{Patient course}

The patient was treated with ibuprofen in the emergency department and discharged with a naproxen prescription. He was referred to his primary care physician for further work-up. The pain improved in the days following his emergency department visit, resolving within a week of discharge. The patient was contacted two months after his emergency department visit. He noted that he was still able to appreciate a firm mass in his chest wall with some reduction in size since it was first diagnosed.

\section{Discussion}

Thrombophlebitis of the subcutaneous veins, also known as Mondor's disease, was first described in 1939 by Henry Mondor as "string phlebitis" [2]. Mondor's disease has been associated with many inciting processes, including muscular strain, repetitive movement of the arm, trauma, inflammatory processes, surgery, biopsy, infection, and breast carcinoma; however, a specific etiology is frequently not identified [2].

Mondor's disease may present either unilaterally or bilaterally [4]. It is reported more frequently in women than men by a ratio of 3:1 [5]. In females, Mondor's disease is most often related to breast surgery or trauma [6]. In males, penile Mondor's is frequently associated with sexual activity [7]. Mondor's disease can reoccur multiple times but is not usually considered a chronic condition [8].

The diagnosis of Mondor's disease is primarily clinical, although CT and ultrasound can be utilized when the diagnosis is in question. Ultrasound can reveal non-compressibility and echogenicity $[2,9,10]$. Color Doppler can also reveal a lack of blood flow upon initial presentation and return of perfusion upon recanalization during the healing process [3,9]. It can be mistaken for a lymphangitis and in the case of penile Mondor's disease, sexually transmitted infections and Peyronie's disease should also be taken into consideration [3]. As Mondor's disease has been associated with potentially severe etiologies such as hypercoagulability, inflammatory conditions, and breast carcinoma, consideration should be given to evaluating these conditions $[2,5]$.

Mondor's disease is ultimately a benign process, and thus its treatment is largely symptomatic $[5,11]$. Treatment with non-steroidal anti-inflammatory drugs and warm compresses are often sufficient for resolution of symptoms [12]. Recommendations for the treatment of superficial thrombophlebitis more broadly do include four weeks of low molecular weight heparin as per the American College of Chest Physicians, and while cases of such an approach to Mondor's disease specifically do exist, treatment is typically more conservative [13]. For female patients with Mondor's disease of the breast, topical diclofenac sodium patches have been used to inhibit prostaglandin-mediated inflammation [14]. When it is located in the axillary region, it may also be possible to manually disrupt the fibrosis with applied pressure [3]. Lastly, in cases of persistent symptoms, excision of the vein may be necessary [12]. Although biopsies were once part of the work-up of Mondor's disease, they are no longer recommended due to its self-limited course $[3,5]$. 


\section{Conclusions}

Thrombophlebitis of the chest wall (Mondor's disease) is a benign cause of chest pain, which can mimic more serious etiologies. The diagnosis can be made on the basis of a thorough history and physical examination, with imaging and laboratory testing only needed to exclude more concerning diagnoses. The treatment is usually symptomatic, although low molecular weight heparin has been used in some cases. Failure to consider Mondor's disease in the chest pain patient can result in increased cost and unnecessary testing. As such, it is crucial that practitioners keep Mondor's disease in the differential diagnosis when approaching localized chest pain with a palpable mass.

\section{Additional Information \\ Disclosures}

Human subjects: Consent was obtained by all participants in this study. Conflicts of interest: In compliance with the ICMJE uniform disclosure form, all authors declare the following: Payment/services info: All authors have declared that no financial support was received from any organization for the submitted work. Financial relationships: All authors have declared that they have no financial relationships at present or within the previous three years with any organizations that might have an interest in the submitted work. Other relationships: All authors have declared that there are no other relationships or activities that could appear to have influenced the submitted work.

\section{References}

1. UpToDate: Evaluation of the adult with chest pain in the emergency department . (2018). Accessed: January 13, 2019: https://www.uptodate.com/contents/evaluation-of-the-adult-with-chest-pain-in-the-emergencydepartment?search=chest\%20....

2. Álvarez-Garrido H, Garrido-Ríos AA, Sanz-Muñoz C, Miranda-Romero A: Mondor's disease. Clin Exp Dermatol. 2009, 34:753-756. 10.1111/j.1365-2230.2009.03430.x

3. Amano M, Shimizu T: Mondor's disease: a review of the literature. Intern Med. 2018, 57:2607-2612. 10.2169/internalmedicine.0495-17

4. Olfield MC: Mondor's disease: a superficial phlebitis of the breast . Lancet. 1962, 1:994-996. https://doi.org/10.1016/S0140-6736(62)92034-2

5. Mayor M, Burón I, De Mora JC, et al.: Mondor's disease. Int J Dermatol. 2000, 39:922-925. 10.1046/j.13654362.2000.00018.x

6. Goldman A, Wollina U: Mondor's disease after aesthetic breast surgery: a case series and literature review . J Cutan Aesthet Surg. 2018, 11:132-135. 10.4103/JCAS.JCAS_69_18

7. Hamilton J, Mossanen M, Strote J: Mondor's disease of the penis. West J Emerg Med. 2013, 14:180. 10.5811/westjem.2012.8.13276

8. Elsahy NIM: Recurrent mondor's disease after augmentation mammoplasty . Aesthetic Plast Surg. 1983, 7:259-260. https://doi.org/10.1007/BF01570673

9. Manimala NJ, Parker J: Evaluation and treatment of penile thrombophlebitis (Mondor's disease). Curr Urol Rep. 2015, 16:39. https://doi.org/10.1007/s11934-015-0512-z

10. Vijayalakshmi AA, Anand S: Mondor's disease. N Engl J Med. 2017, 376:47. 10.1056/NEJMicm1611550

11. Samlaska CP, James WD: Superficial thrombophlebitis II. secondary hypercoagulable states. J Am Acad Dermatol. 1990, 23:1-18. https://doi.org/10.1016/0190-9622(90)70179-L

12. Parker CC, Damodaran S, Bland KI, Hunt KK : "The breast". Schwartz's Principles of Surgery, 11e. Brunicardi F, Andersen DK, Billiar TR, et al. (ed): McGraw-Hill, New York, NY; 2018.

13. Kearon C, Kahn SR, Agnelli G, et al.: Antithrombotic therapy for venous thromboembolic disease: American College of Chest Physicians evidence-based clinical practice guidelines (8th Edition). Ches. 2008, 133:454545. https://doi.org/10.1016/j.chest.2015.11.026

14. Shirah BH, Shirah HA, Alonazie WS: The effectiveness of diclofenac sodium in the treatment of Mondor's disease of the breast: the topical patch compared to the oral capsules. Breast J. 2017, 23:395-400. $10.1111 /$ tbj. 12752 